Slavica

bruxellensia

\section{Slavica bruxellensia}

Revue polyphonique de littérature, culture et histoire

slaves

$8 \mid 2012$

Migration(s) et Exil(s)

\title{
Interpretować dalej. Najważniejsze polskie ksiĄżki poetyckie lat 1945-1989, Kałuża A. \& Świeściak A. (dir.)
}

\section{Małgorzata Wesołowska}

\section{OpenEdition}

\section{Journals}

Édition électronique

URL : http://journals.openedition.org/slavica/1093

DOI : 10.4000/slavica.1093

ISSN : 2034-6395

\section{Éditeur}

Université libre de Bruxelles - ULB

\section{Référence électronique}

Małgorzata Wesołowska, «Interpretować dalej. Najważniejsze polskie książki poetyckie lat 1945-1989, Kałuża A. \& Świeściak A. (dir.) », Slavica bruxellensia [En ligne], 8 | 2012, mis en ligne le 28 juin 2012, consulté le 22 septembre 2020. URL : http://journals.openedition.org/slavica/1093 ; DOI : https:// doi.org/10.4000/slavica.1093

Ce document a été généré automatiquement le 22 septembre 2020.

\section{c)}

Les contenus de Slavica bruxellensia sont mis à disposition selon les termes de la Licence Creative Commons Attribution - Pas d'Utilisation Commerciale - Pas de Modification 3.0 France. 
Interpretować dalej. Najważniejsze polskie ksiĄżki poetyckie lat 1945-1989, Kałuża A. \& Świeściak A. (dir.)

Małgorzata Wesołowska

\section{RÉFÉRENCE}

Interpretować dalej. Najważniejsze polskie książki poetyckie lat 1945-1989, Kałuża A. \& Świeściak A. (dir.), Universitas, Cracovie, 2011, 540 p.

\section{NOTE DE L'ÉDITEUR}

Traduit du polonais par Katia Vandenborre 
1 Comment écrire l'histoire de la littérature de manière à s'écarter de la dominante historico-littéraire, de manière à échapper à la constitution de canons, de classifications ou d'ordonnancements artificiels? La dernière anthologie consacrée à la poésie polonaise, intitulée Interpretować dalej. Najważniejsze polskie ksiazżki poetyckie lat 1945-1989 (Interpréter, plus loin, encore. Les livres poétiques polonais les plus importants des années 1945-1989), peut être une réponse à cette question. L'utilisation de l'adjectif najważniejsze («les plus importants») est une forme d'appréciation autoritaire. Les rédactrices de l'ouvrage avouent toutefois dans leur introduction que «ce n'est pas un corpus complet d'œuvres qui est en jeu » (p. 7) mais bien un choix personnel des livres poétiques «les plus

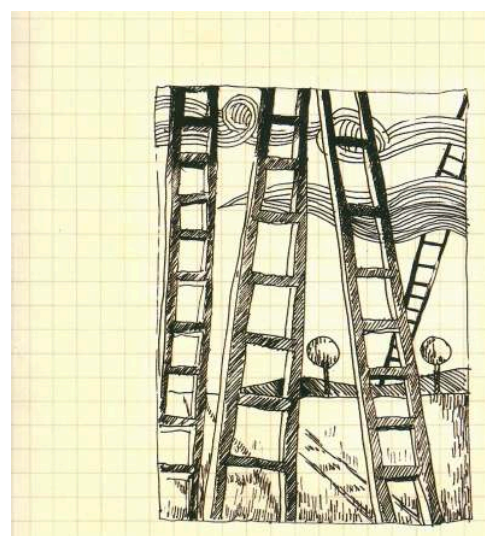
importants» effectué librement par les auteurs et (très nombreuses) auteures des trente-quatre esquisses. L'ouvrage est exceptionnel dans la mesure où il ne constitue ni un recueil d'interprétations de poèmes isolés (comme par exemple Lirykapolska [La poésie lyrique polonais], sous la direction de Jan Prokop et de Janusz Sławiński ${ }^{1}$ ) ni une monographie de l'œuvre d'un auteur. L'anthologie se compose de textes consacrés à des recueils poétiques, dont ceux de Władysław Broniewski, Konstanty Ildefons Gałczyński, Stanisław Czycz, Zbigniew Herbert, Czesław Miłosz, Halina Poświatowska, Tadeusz Różewicz, Stanisław Grochowiak, Wisława Szymborska, Jarosław Iwaszkiewicz, Tymoteusz Karpowicz : la liste est vraiment longue. Ce " canon », qui ne prétend ni être un modèle ni être clos, s'est constitué grâce à la contribution de différentes voix (tant celle des poètes que celle des auteurs des textes). Ainsi, les interférences entre les textes, les poètes et les auteurs du recueil constituent le trait le plus significatif de cette structure polyphonique. Le dialogue y est effectivement mené à plusieurs niveaux : premièrement, des auteurs particuliers discutent avec l'œuvre des poètes qu'ils ont choisis ; deuxièmement, des poètes particuliers sont amenés à dialoguer entre eux via la mise en parallèle de leurs créations dans une même esquisse (comme le fait Anna Legeżyńska en confrontant les œuvres politiques de Stanisław Barańczak et de Kazimierz Wierzyński) ; enfin, troisièmement, tous les textes " conversent » entre eux, esquissant ainsi la riche constellation de la poésie polonaise d'après-guerre et de la période communiste.

2 De cette manière, l'anthologie reflète l'histoire de la poésie polonaise (les esquisses sont classées par ordre chronologique, depuis la poésie de Broniewski à celle de Barańczak), mais c'est une histoire qui n'a pas la transparence de certains compendiums ou travaux d'histoire littéraire ; chacun des auteurs signale très clairement sa position personnelle dans l'interprétation. Les auteurs et auteures des esquisses mettent au premier plan ce qui jusqu'ici se trouvait au second : ils présentent l'œuvre des poètes dans un nouveau 
contexte, par exemple éco-critique (Broniewski dans l'interprétation de Grzegorz Jankowicz), politique (le Przyboś d'Igor Stokfiszewski) ou encore économique (Gałczynśki dans l'interprétation de Beata Mytych-Forajter et Wacław Forajter). Le « regard distancié » semble jouer ici un rôle clé. Comme l'écrit Andrzej Skrendo dans son analyse du recueil Hermes, pies i gwiazda (Hermès, le chien et l'étoile) de Herbert, certaines choses «ne peuvent être vues qu'avec une plus grande perspective» (p. 82): grâce aux nouveaux outils de critique littéraire et de méthodologie, les premières interprétations, les interprétations les plus anciennes de poètes particuliers peuvent être vérifiées ou complétées. Une nouvelle optique permet aux auteurs des esquisses d'inscrire l'œuvre des poètes choisis dans un contexte plus large: européen, contemporain. Le «regard distancié » n'est pas non plus dépourvu de précision: les réflexions à caractère littéraire en général sont accompagnées d'analyses détaillées d'œuvres poétiques (par exemple, dans son esquisse sur Mylne wzruszenia [Émotions trompeuses] de Miron Białoszewski, Kacper Bartczak montre les implications de la philosophie de Donald Davidson dans l'interprétation de la poésie en général).

Un fait mérite encore d'être relevé: parmi les éminents auteurs certains n'appartiennent pas au milieu académique, ce qui renforce l'impression de polyphonie de la publication et adoucit son caractère « institutionnel ». Ce livre, en tant que lieu de conversation entre des «moi» d'auteurs multiples (poètes et interprétateurs), démontre parfaitement que l'interprétation n'est jamais uniforme, finie ou fermée : elle continue toujours in profondo continuo. Plus loin. Encore.

\section{NOTES}

1. Liryka polska. Interpretacje (La poésie lyrique polonaise. Interpretations), Prokop J. \& Sławiński J. (dir.), Słowo/Obraz Terytoria, Gdańsk, 2002, 614 p.

\section{INDEX}

Index géographique : Pologne

Index chronologique : communisme, XXe siècle

Mots-clés : littérature polonaise 


\section{AUTEURS}

\section{MAŁGORZATA WESOŁOWSKA}

Doctorante en Littérature comparée à l'Université de Szczecin (Pologne). Diplômée de Polonistique et de Linguistique appliquée de la même université. 